\title{
Toward a Web-Integrated Solution for Flood Observations
}

\author{
P. Limlahapun and H. Fukui
}

\begin{abstract}
Floods are natural disasters that can be difficult to predict, as there are no obvious time or location factors. This study aims to improve flood-forecasting models in order to analyze rainfall discharge and to investigate the threshold values for conveying alert messages. Improvements of the operation of existing software-based resources are made by providing a simple interface on a Web-based system that conducts the analysis by eliminating redundant steps from the computation procedure and making it available beyond a stand-alone operation. Topography, rainfall, soil and land cover are main factors for a flood-forecasting model. Among them, rainfall is considered a driving factor with spatial-temporal aspects. Hydrological data such as Tropical Rainfall Measuring Mission (TRMM) acquired through Internet communication is used to analyze rainfall discharge and informative flood analysis as a near real-time data source. The rainfall discharge distribution in the Wangthong watershed is proposed as an example of the worldwide use of TRMM data. The TRMM satellite is proving its worth regarding precipitation data, particularly for those areas where rainfall measuring is not practical. An integrated geospatial Web-based system is established to facilitate public awareness by allocating information in a timely manner without the need for cumbersome software installation.
\end{abstract}

Index Terms-Flood, rainfall-runoff, monitoring system, warning system, spatial data infrastructure.

\section{INTRODUCTION}

All Flood disasters may cause tremendous damage if not properly controlled. Regular observations help to reduce the severity of the impact [1] and efficiently reduce the risk to the community. Identification of the critical areas aids environmental prevention managers in better management of the watershed and surrounding communities. An increasing number of real-time flood monitoring, forecasting and early warning systems have been developed, but extensive research efforts are still challenging. The factors that cause floods are often the focus of physical studies [2] that involve climate and meteorological data, topography (e.g., elevation), and satellite images. This paper is mainly intended to evaluate rainfall and topographical data and to propose solutions to improve flood analysis models in order to develop monitoring and early alert systems. The changes in rainfall and discharge distribution over the watershed can be predicted for the prevention and reduction of potential flood damage. Therefore, Tropical Rainfall Measuring Mission (TRMM)

Manuscript received January 13, 2015; revised May 13, 2015.

P. Limlahapun with the Japan Society for the Promotion of Science, the International Digital Earth Applied Science Research Center, Chubu University, 12000 Matsumoto-cho, Kasugai, Aichi, Japan (e-mail: thip.limlahapun@gmail.com).

H. Fukui with the International Digital Earth Applied Science Research Center, Chubu University, 12000 Matsumoto-cho, Kasugai, Aichi, Japan (e-mail: fukui@isc.chubu.ac.jp). rainfall data are used to acquire information and perform near real-time data transmission [3]. A flood forecasting model improvement was performed in order to reduce time of operation. This was done through a spatially Web-based infrastructure that was developed to increase efficiency of information sharing and to convey the outcome of a flood alert analysis - a tool for the immediate transference of emergency messages to the public.

\section{PRoblem Statement}

The reasons for this study are summarized as follows. First, the assessment and analysis of this research is conducted by the Integrated Flood Analysis System (IFAS) as a backend system. IFAS is a software operation that is useful for flood analysis. However, the original IFAS model is processed in a serial-based manner, which completes computation gradually. Second, flood monitoring assessment uses rainfall as one of the parameters in the calculation of the model; however, the application of near real-time rainfall data to flood risk assessment is still limited. Third, the Wangthong watershed has been a focal point of several management programs in recent years. Several projects have been investigated to control potential disasters (e.g., floods) within the watershed. Still, there has been no systematic automated monitoring in the watershed or distribution of information to the public. Fourth, the analysis outcome will provide useful information that is transferrable to many areas and to the local community that may be affected. In developing countries (e.g., Thailand, per the authors' experience), information that is available online is more likely to be presented; however, data (e.g., geo-spatial data) from trusted agencies (e.g., the government) are still rare.

\section{RELATED WORKS}

There have been several approaches and case studies related to this field of study. The TRMM satellite was the first dedicated observation satellite [3] to observe precipitation data. It is designed to measure rates of rainfall from space using combinations of high-resolution radar and passive microwave and visible-infrared radiometer measurements [1]. More recently, several research studies have been successfully conducted that estimate rainfall from satellite images [3], one of the most utilizable rainfall datasets that was derived from TRMM [4]. For example, Bindish et al. [5] estimated that soil moisture mapping results from the TRMM data for the southern Great Plains of the United States, Oklahoma and the Little River Watershed, Georgia were consistent with ground meteorological observations. Collischonn et al. [4] also showed that TRMM-based hydrograph calculation results were promising compared with 
those generated from rain gauge data. Similarly, Omotosho and Oluwafemi [6] analyzed the thunderstorm ratio (the total rain accumulation and one-minute incremental rainfall rates) in Nigeria.

A positive correlation was drawn from results using TRMM data and data collected from the field. With the corroboration of several research teams, the TRMM satellite is proving its worth with its accurate precipitation data, particularly for those areas where rainfall measuring is not practical. An immediate response to a flood event is critical to any disaster management program. An increased amount of real-time flood forecasting has been taking place; however, extensive research efforts are still required to face challenge of integrating data [7] in order to optimize computation rates and to increase visualization capabilities.

Holdaway [8] posed a remarkable question asking whether a disaster warning and monitoring system exists. Recently, different applications have been used Internet communications not only to obtain access to data source but also to distribute the outcome more rapidly. Kanwar et al. [9] developed a system to distribute hydrologic data over a Web-based service [10] in an effort to provide an easier way to integrate data sources into hydrological models [11]. Numerous natural disaster information services have been launched and are provided online through reliable organizations such as Sentinel Asia, the Global Disaster Alert and Coordination System (GDACS), the U.S. Geological Survey (USGS), and AlertNet, which alerts humanitarians about emergencies. Grasso and Singh [12] developed a similar alert database system called the Global Environmental Alert Service (GEAS), which provides a map showing the locations and types of disasters, such as earthquakes, tsunamis, volcanic eruptions, and floods. GEAS also sends e-mail alert messages.

Based on literature reviews, numerous well-functioning systems and an abundance of information are available. Still, systematic research could be performed to strengthen the use of facilities designed to investigate the current situation and to manage information in an effective way. Prior flood management has been conducted using the IFAS flood forecasting model to analyze rainfall-discharge intensity and to evaluate threshold values for the warning process. The contribution of the new proposed system is to reduce operating time consuming. The original IFAS model based on step-wise processing, the proposed system then operates in parallel-based computation; automatically pre-downloading data; avoid wire transferring; and eliminating unnecessary graphic-output.

\section{FRAMEWORK OF THE STUDY}

The study area and procedures for the assessment of rainfall are discussed in the following sections.

\section{A. Study Area}

The area of interest is the Wangthong watershed, which is one of the tributaries of the Nan River (Fig. 1). The watershed covers approximately 2,000 square kilometers of the drainage area. Most of the areas located upstream are mountainous, while those located downstream are mostly flood plains. The downstream area is connected to the Nan River, which makes drainage difficult, leading to yearly floods, especially in the Wangthong district of Phitsanulok Province. The topography of the flood plain resembles a pan-like shape that could result in longer periods of flood occurrences. The area's main crops are rice, maize, cassava, fruits and vegetables. Rainfall in this area is influenced by tropical monsoon. The annual average temperature is approximately 27 degrees Celsius, and the annual rainfall is approximately $1,400 \mathrm{~mm}$. A precipitation period from August to October, with the wettest month being September, has been recorded for a 30-year period from 1978 -2008 [13].

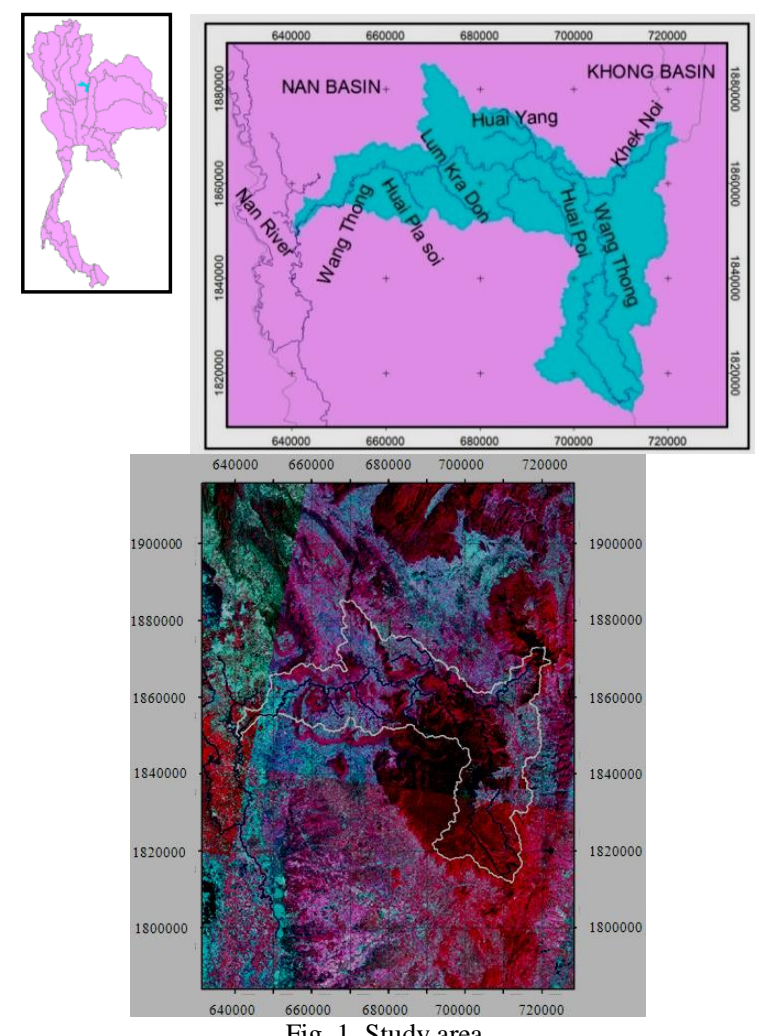

\section{B. System Overview}

Datasets, including a digital elevation model (DEM), land cover, soil, and TRMM are managed in a geographic database. These datasets are used to analyze the relationships between rainfall intensity and the amount of discharge in the river network. The amount of discharge, which is kept in the database, is queried and transferred to the alert system if it exceeds the preset threshold value to perform a pre-flood period response. The overall system is shown in Fig. 2 details for each task are described below.

\section{1) Task 1: Rainfall and river monitoring}

Rainfall is the most variable of the input parameters. Therefore, the three-hourly TRMM rainfall dataset is treated as near real-time data. TRMM data are available for free online access at ftp://trmmopen.gsfc.nasa.gov.pub/merged. A comma-separated values (CSV) file, which includes time, rainfall, river discharge, and grid cell location, is converted to a compatible format and inserted into the PostgreSQL database. The threshold values corresponding to the peak discharge return period are set for the warning system. The amount of discharge, which is kept in the database, is queried 
and transferred to the alert system if it exceeds the preset threshold value. The rainfall distribution over the Wangthong watershed is shown to have improved visualization over the entire watershed system. Gridded Binary (GRIB) data were used to simulate a spatial rainfall-based distribution through the Weather Research and Forecasting (WRF) atmospheric model. Six-hourly weather data, such as temperature, humidity, wind, and sunlight duration, are also available free downloading at http://rda.ucar.edu [accessed on September 2013].

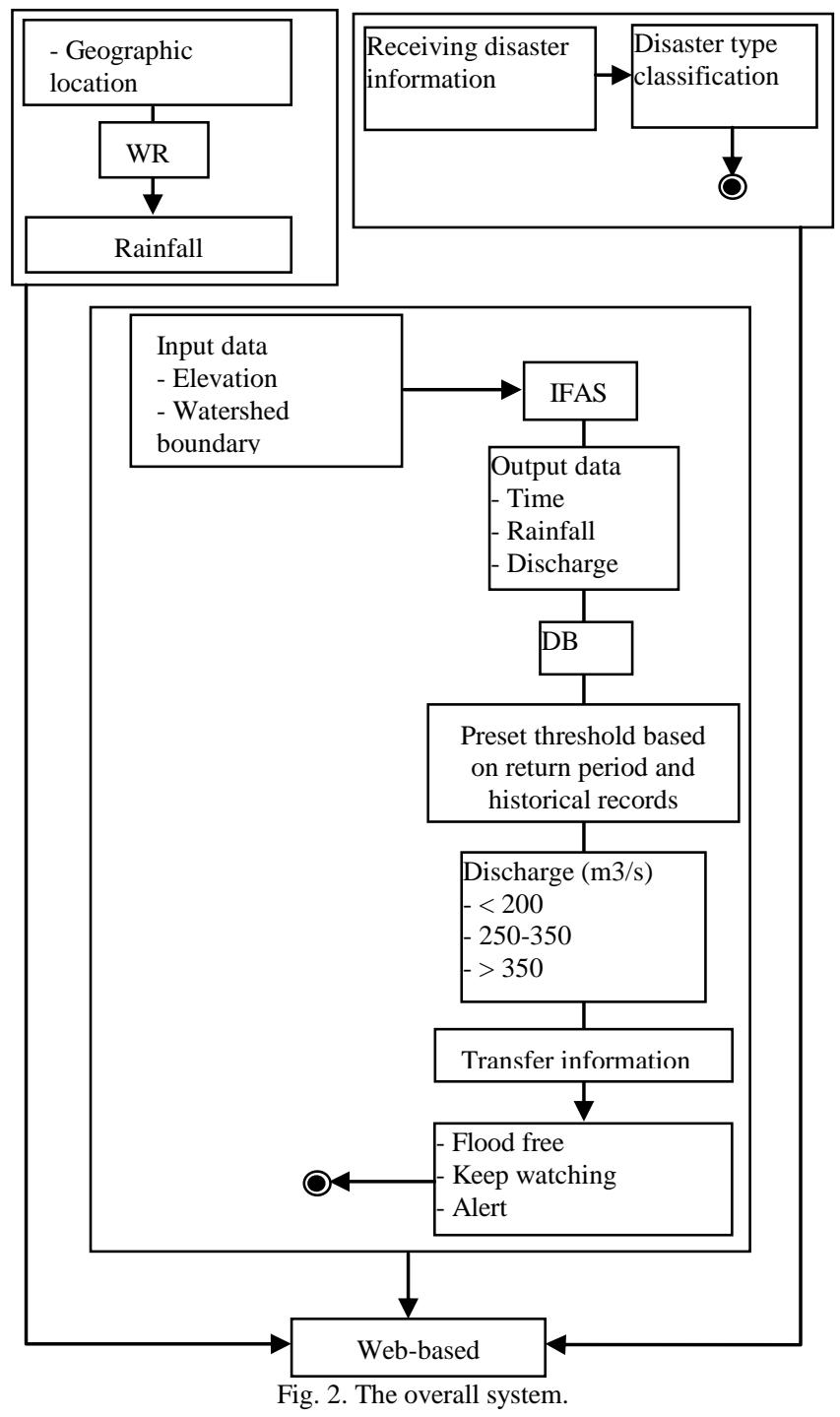

\section{2) Task 2: Improvement of IFAS flood analysis model}

The original IFAS model is a graphic-based selection [14] and step-wise processing system. A project is initiated and the location and time period are identified by users. TRMM rainfall is then downloaded. The software will simulate the results of a rainfall-discharge hydrograph. IFAS is useful and performs its promised result; howver, its disadvantage is that data are deleted once users identified to a new area and/or time operation period.

Fig. 3 shows the proposed system: processing in parallel-based computation through the Web-based system. The proposed system will reduce time using PHP programming commands and database operations. The user will select a date and time period through the interface (with starting date and end date). The integration of rainfall data links from the original source and the IFAS proved to be an efficient tool for watershed rainfall-discharge analysis. The receiving rainfall TRMM data function ensures up-to-date data. Regularly pre-downloading data can reduce the processing time compared with the original import data function in the IFAS model and can avoid wire transfer downloading problems.
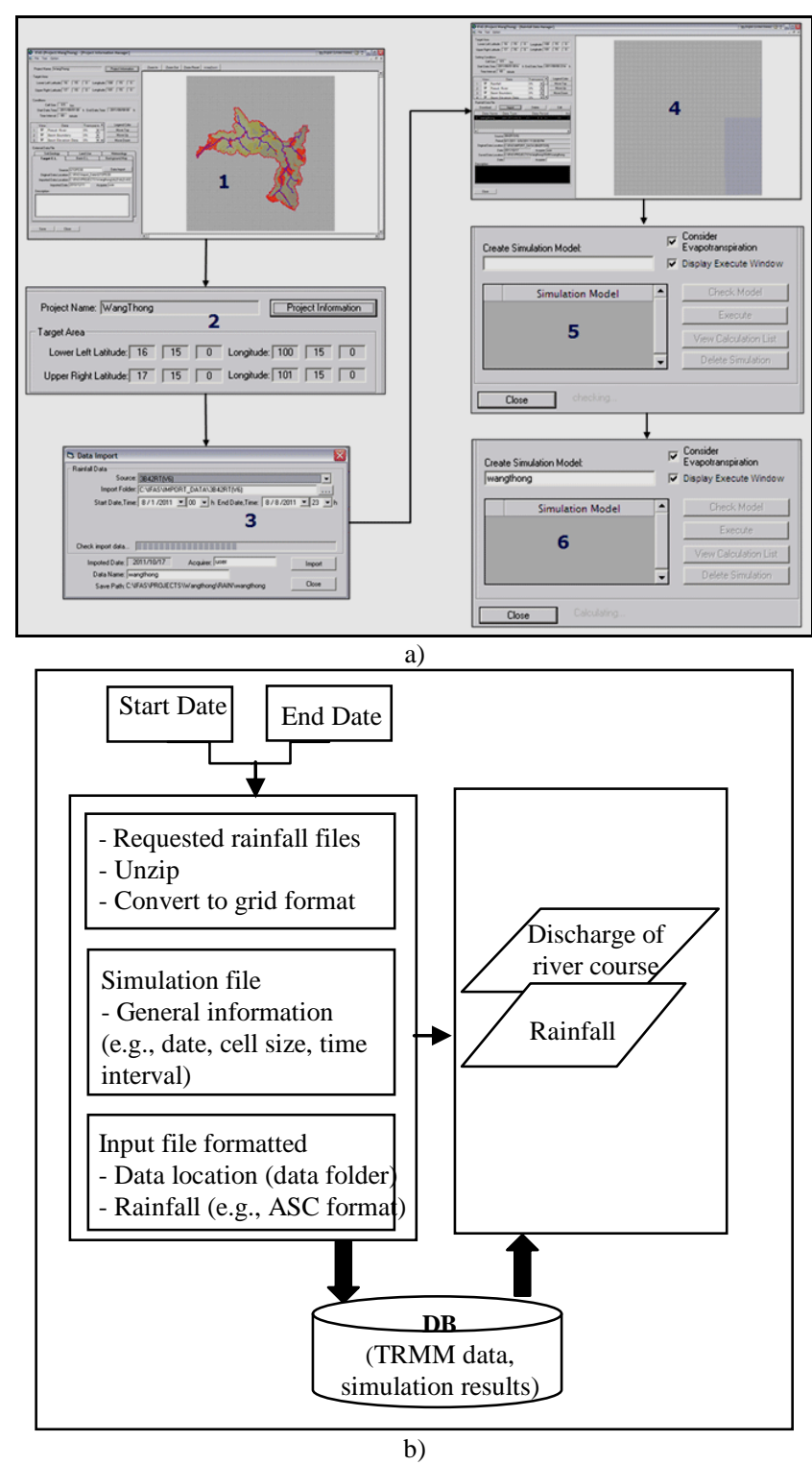

Fig. 3. a) Original IFAS interface; b) Proposed operation of web-based system.

A field survey was also conducted to monitor the dry season in April and the wet season in August. An expansion of the effective functionality hydrograph is embedded into a geospatial web-based system, which is based on a Mapbender package. A Web application for the data exchange mechanism is used to link the systems. The system is therefore specially used to bring precipitation and auto-exchanging to a common usable image format.

\section{RESUlt}

The proposed system is based on simplicity of service; however, the complexity modules behind the system ensure 
that: 1) information is delivered in an informative form; 2) efficiency of use is not sacrificed to ease of use; 3) the clarity of the system prevents users from interacting with inappropriate functions or data; and 4) there is adherence to standards. A daily assessment of rainfall was proposed for the regular monitoring of risk-prone areas. A hydrograph showing the rainfall-runoff for a specific time period could be displayed. The rainfall-runoff monitoring system processes information via a Web-based sharing system [15] that can be deployed to more users. Rainfall and discharge in the years of 2005 and 2010 were used to compare and evaluate, using TRMM (three-hourly) rainfall, meteorological data used in IFAS, the WRF model, and Geographic Information System (GIS). IFAS was used to generate a hydrograph. The WRF was used to simulate rainfall patterns in spatial-based manner.

\section{A. Analysis of Rainfall Data and River Monitoring}

The study area was located between latitudes 16150 and 17150 and longitudes 100150 and 101150 . This section of the study assessed three-hourly rainfall, land cover, soil water capacity, topography data and watershed boundaries. Then, the amount of rainfall and discharge simulated in the watershed between the months of August and September from 2005 to 2010 were estimated. Finally, based on the results, hydrographs were presented to facilitate a discussion of the relationship between rainfall and discharge along the river.

Fig. 4 shows the grid locations where discharge was observed. The discharge is presented in cubic meters per second $\left(\mathrm{m}^{3} / \mathrm{s}\right)$ at a given point along the river network. The dominant peak discharge presents, similarly, a pattern along the river in which the flow amounts increase from east to west, which reflects the flood plain elevation within the watershed areas. However, the observed point may be reduced because of similar results. The peak discharges at the outlet cell (G11) were approximately 474 and $466 \mathrm{~m}^{3} / \mathrm{s}$ at $11 \mathrm{PM}$ on September 29, 2005 and at $10 \mathrm{AM}$ on September 27, 2010, respectively, as shown in Fig. 5.
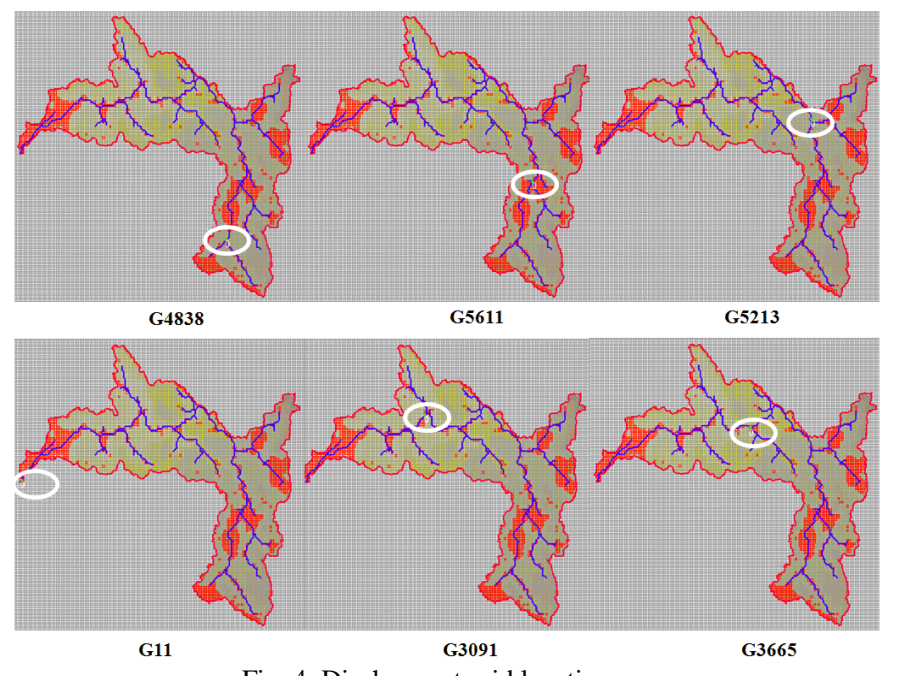

Fig. 4. Discharge at grid locations.

\section{B. Analysis of Meteorological Data and Rainfall Observation}

The 2005 and 2010 24-hour rainfall distribution of the Wangthong watershed is shown in Fig. 6. The rainfall distributions were derived from the WRF model, which was georeferenced and overlain with the watershed boundary. On September 29, 2005, rainfall continued throughout the day, starting at midnight. Tremendous rainfall intensity occurred from $12 \mathrm{PM}$ to $2 \mathrm{PM}$. The rainfall pattern was concentrated in the east and northeast portions of the watershed, both of which have high altitudes. The rainfall continued throughout the day and increased in intensity downstream at 11 PM. Similarly, the rainfall pattern began in the early morning and continued throughout the day on September 27, 2010. From 5 AM to 11 $\mathrm{PM}$, the rainfall was distributed throughout the watershed area. The precipitation that fell from $12 \mathrm{PM}$ to $3 \mathrm{PM}$ presented greater intensity and covered the watershed areas.
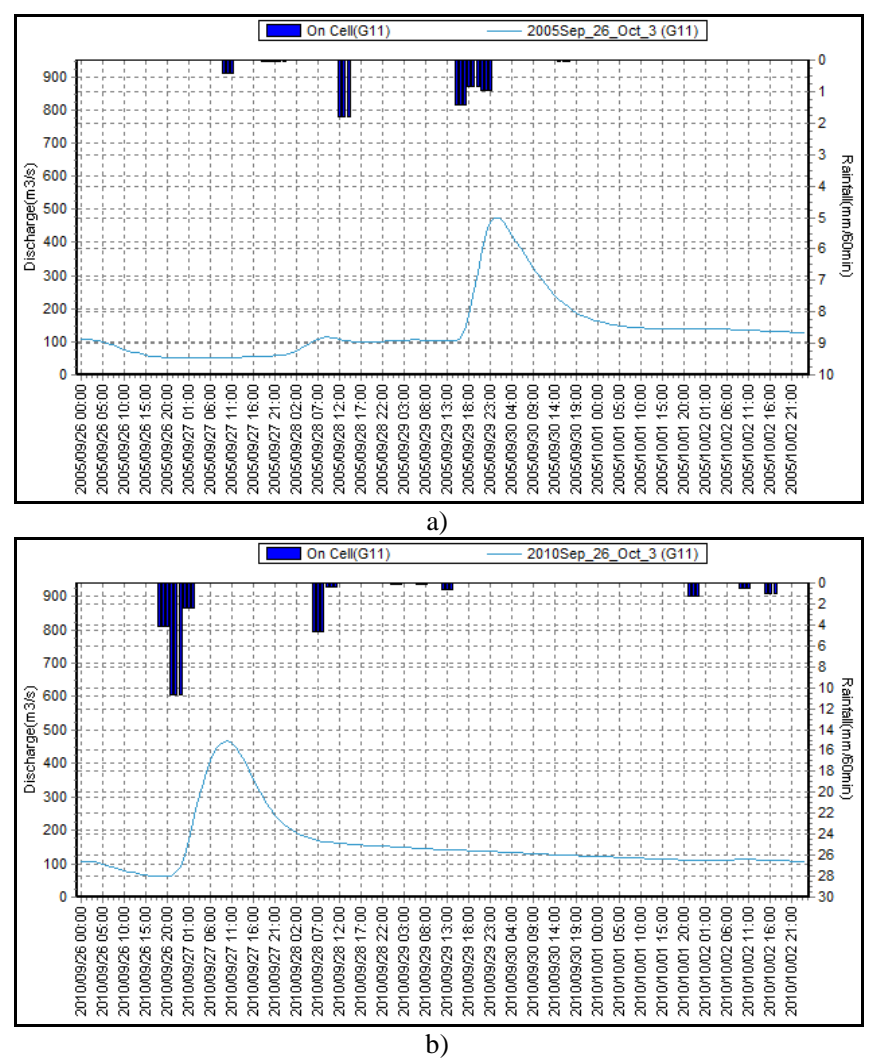

Fig. 5. Simulated hydrographs: a) September 26-October 2, 2005; b) September 26-October 2, 2010.

The WRF uses atmospheric six-hourly data to generate rainfall amounts. The processing time is approximately 12 minutes per hour, or 5 hours per day, of data loading. Obtaining rainfall image results is time consuming. The results show the phenomena of rainfall and discharge over areas and time periods. This method undoubtedly provides a better visualization to spatially represent the relationship between precipitation and discharge.

\section{An Alert System}

This study investigated river profiles and return periods, as shown in Fig. 7. Ultimately, based on the analysis, the threshold value was set in relation to the peak discharge return period and the historical flood data. The alert system was classified into three levels associated with the peak discharge return period: flood-free, keep watching, and flood warning for discharge values below 200, between 250 and 350, and above $350 \mathrm{~m}^{3} / \mathrm{s}$, respectively. The system will check the database and send messages automatically through a 
PHP-mailer as a support system.

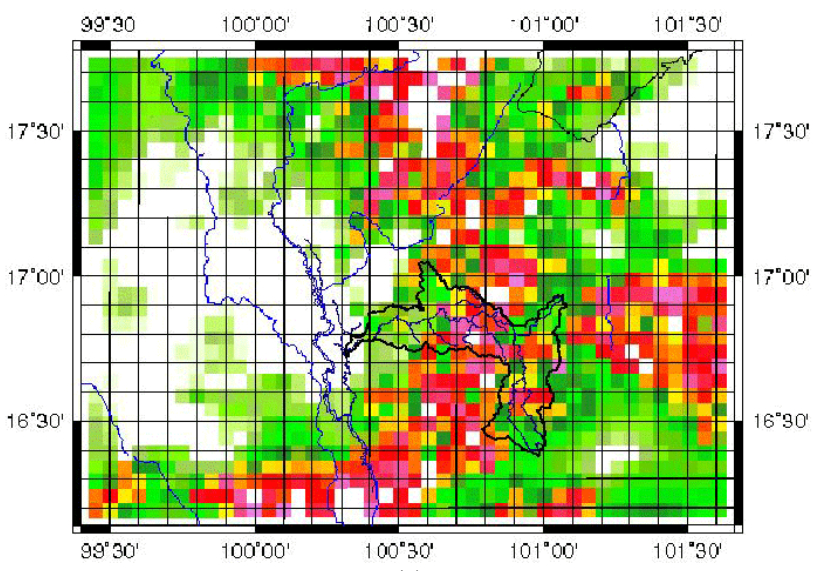

(a)

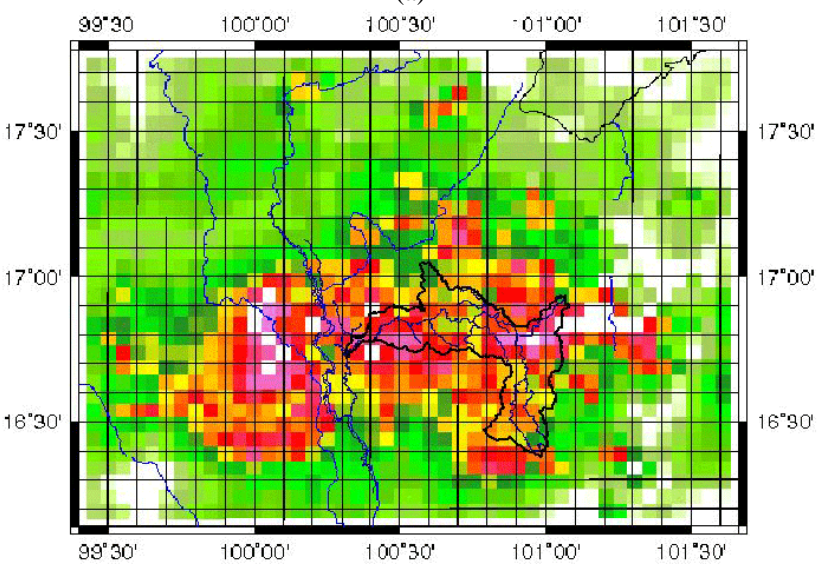

(b)

Fig. 6. Rainfall distribution: a) 12 PM on September 29, 2005; b) 2 PM on September 27, 2010.

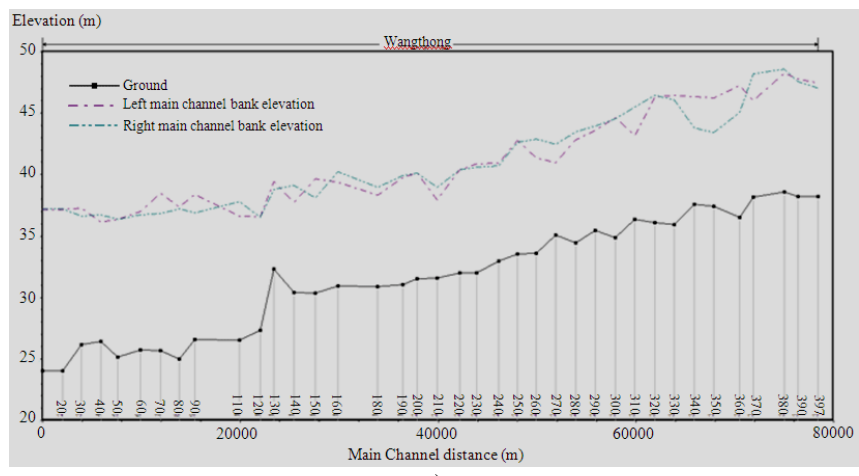

a)

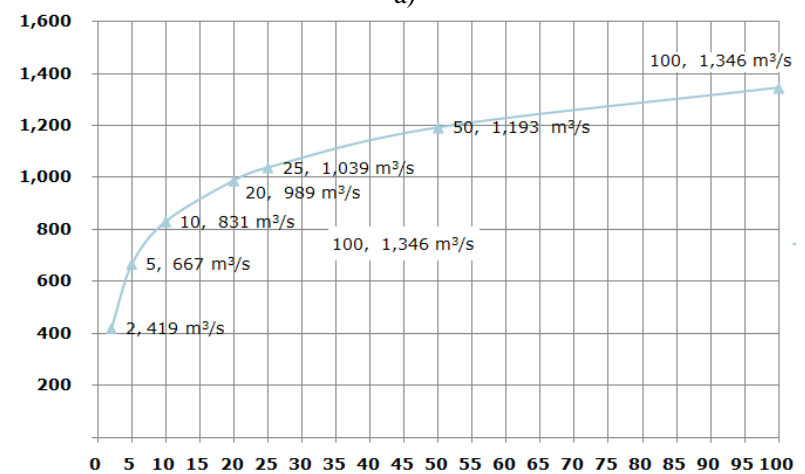

b)

Fig. 7. a) River profile; b) Return period.

\section{Field Survey}

A field survey was conducted to monitor flood situations and communicate with local people. During the field survey, which was conducted during the wet season, it was found that the water level rose in the downstream areas while the setting upstream was still in the secure stage. The significant issue was raised during discussions with a leader of the community, indicating that the water level measurement instrument proved to be set precisely for warning level (Fig. 8).
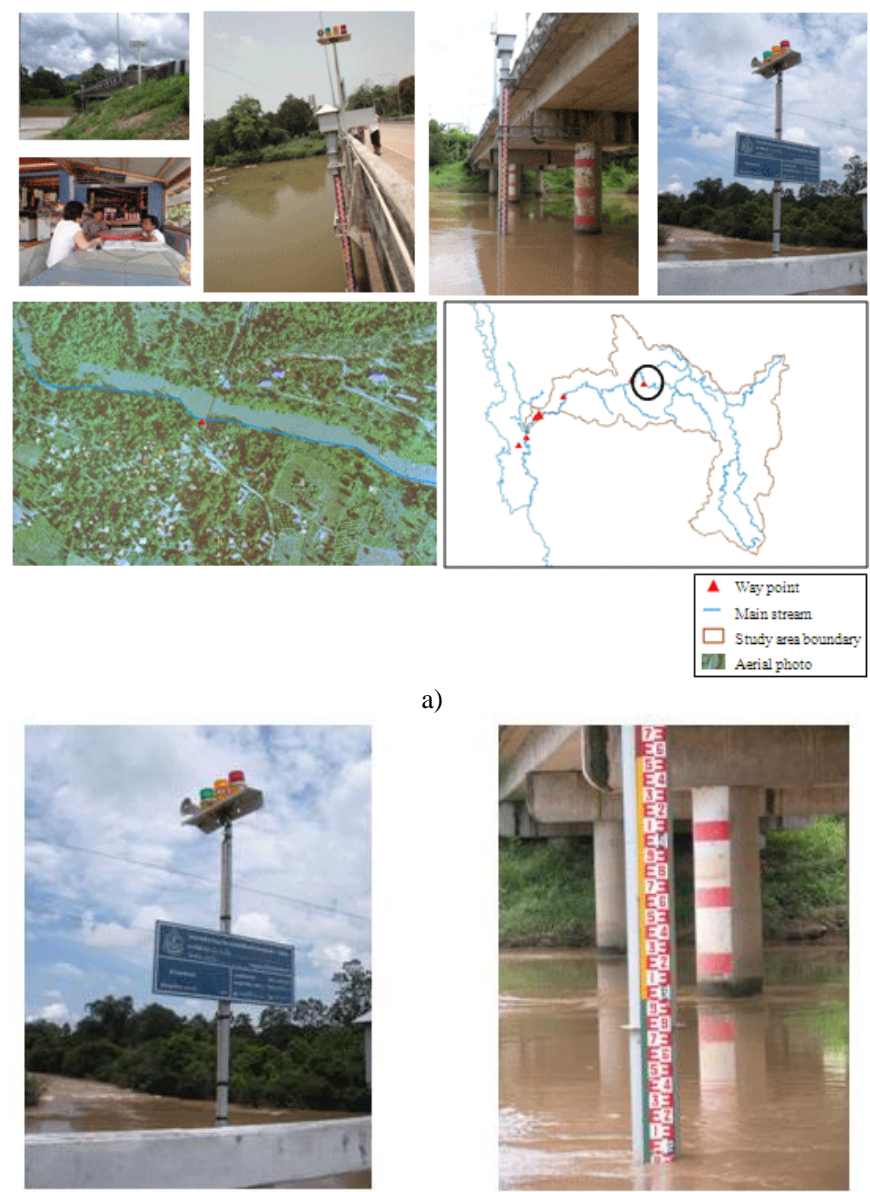

b)

Fig. 8. a) Water level and warning station, Bann Tha Kam, Wangthong River; b) Upstream area.

\section{E. Web-Based System for the Assessment of Disaster Information}

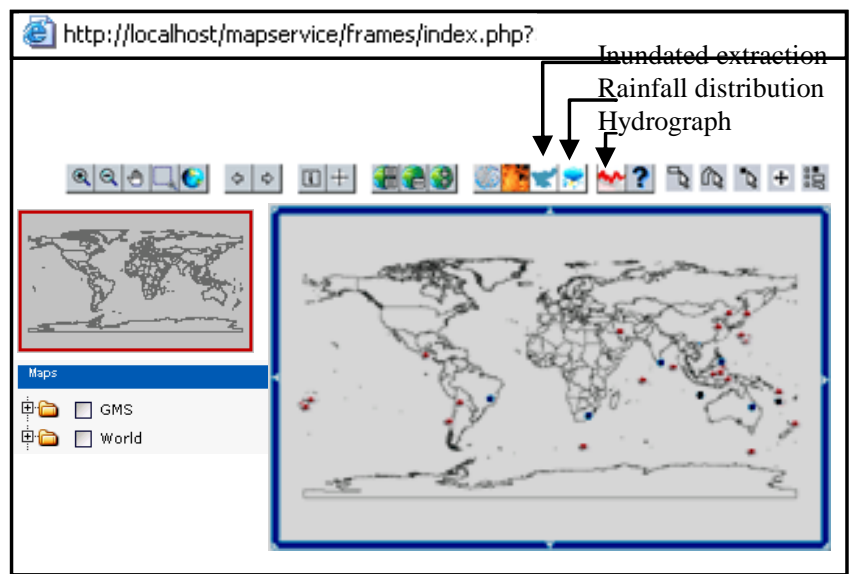

Fig. 9. Geo-spatial web-based system.

A spatial Web-based system was established to facilitate public awareness of a potentially catastrophic event that can be pre-detected and even prevented altogether (Fig. 9). The system also gathers disaster information from geospatial data 
catalog Web services. As a result, spatial information is shared among different sources for the benefit of users. This effort aims to raise awareness by allocating information in a timely manner without the need for cumbersome software installation.

\section{CONCLUSION}

Hydrological processing over a Web-based interface was found to be a valuable tool for predicting the possibility of critical flood distribution in a watershed area, when combined with a graphics-based output. These techniques reduce processing time by eliminating unnecessary procedures from the original IFAS program. Land use, soil, slope, and rainfall have major influences on excess water speed, and they thereby influence the inundated risk. This result can be used by decision makers to prioritize the entire watershed when implementing the best management practices to minimize flood problems. The outcome of this research can also be applied to early warning activities. Satellite rainfall data, such as those obtained from TRMM, are suitable for this type of application because the data can be retrieved frequently even when there is no rain gauge in the area.

The findings showed that the proposed flood-forecasting operation system could be implemented to analyze hydrological data more rapidly than the existing IFAS software. The use of a Web-based system can collect hydrological and meteorological data in a certain way and can rapidly transmit information to the public. This system provides effortless accessibility and reduces the amount of time needed for nonprogrammers to manage the data via an Internet medium such as TRMM. This technology overcomes platform issues and the fixed cost of operation. It will also reduce operating expenses and time consumption. Furthermore, it does not require technical expertise in programming to interpret the rainfall events.

\section{ACKNOWLEDGMENT}

We gratefully acknowledge financial support from Grants-in-Aid for Scientific Research Program by the Japan Society for the Promotion of Science, JSPS KAKENHI Grant Number $\mathrm{xx}$.

\section{REFERENCES}

[1] T. Kawanishi, H. Kuroiwa, M. Kojima, K. Oikawa, T. Kozu, H. Kumagai, K. Okamoto, M. .Okumura, H. Nakatsuka, and K. Nishikawa, "TRMM precipitation radar," Advances in Space Research, vol. 25, issue 5, pp. 969-972, February 2000.

[2] J. S. Theon, "The tropical rainfall measuring mission (TRMM)," Advances in Space Research, vol. 14, issue 3, pp. 159-165, March 1994.

[3] T. Wardah, S. H. Abu Bakar, A. Bardossy, and M. Maznorizan, "Use of geostationary meteorological satellite images in convective rain estimation for flash-flood forecasting," Journal of Hydrology, vol. 356 , issues 3-4, pp. 283-298, July 2008.

[4] B. Collischonn, W. Collischonn, and C. E. M. Tucci, "Daily hydrological modeling in the Amazon basin using TRMM rainfall estimates," Journal of Hydrology, vol. 360, issues 1-4, pp. 207-216, October 2008.

[5] R. Bindish, T. J. J. Jackson, E. Wood, H. Gao, P. Starks, D. Bosch, and V. Lakshmi, "Soil moisture estimates from TRMM microwave imager observations over the Southern United States," Remote Sensing of Environment, vol. 85, issue 4, pp. 507-515, 2003.

[6] T. V. Omotosho and C. O. Oluwafemi, "One-minute rain rate distribution in Nigeria derived from TRMM satellite data," Journal of Atmospheric and Solar-Terrestrial Physics, vol. 71, issue 5, pp. 625-633, 2009.

[7] W. Al-Sabhan, M. Mulligan, and G. A. Blackburn, "A real-time hydrological model for flood prediction using GIS and the WWW," Computers, Environment and Urban SYSTEMS, vol. 27, issue 1, pp. 9-32, 2003.

[8] R. Holdaway, "Is space global disaster warning and monitoring now nearing reality?" Space Policy, vol. 17, issue 2, pp. 127-132, 2001.

[9] R. Kanwar, U. Narayan, and V. Lakshmi, "Web service based hydrologic data distribution system," Computers \& Geosciences, vol. 36, issue 7, pp. 819-826, 2010.

[10] Y. Jia, H. Zhao, C. Niu, Y. Jiang, H. Gan, Z. Xing, X. Zhao, and Z. Zhao, "A Web GIS-based system for rainfall-runoff prediction and real-time water resources assessment for Beijing," Computer \& Geosciences, vol. 35, issue 7, pp. 1517-1528, 2009.

[11] X. Y. Li, K. W. Chau, C. T. Cheng, and Y. S. Li, "A web-based flood forecasting system for Shuangpai region," Advances in Engineering Software, vol. 37, issue 3, pp. 146-158, 2006.

[12] V. F. Grasso and A. Singh, "Global environmental alert service (GEAS)," Advances in Space Research, vol. 41, issue 11, pp. 1836-1852, 2008

[13] Thai Meteorological Department, "Weather of Thailand May-August 2009," Journal of Meteorology, vol. 9, issue 3, pp. 10-11, 2009.

[14] K. Fukami, T. Sugiura, J. Magome, and T. Kawakami, "Integrated flood analysis system (IFAS Version 1.2): User's manual," Public Works Research Institute (PWRI), International Centre for Water Hazard and Risk Management under the Auspices of UNESCO (ICHARM), Publication, no. 14, 2009.

[15] E. Todini, "An operational decision support system for flood risk mapping, forecasting and management," Urban Water, vol. 1 issue 2, pp. 131-143, 1999.

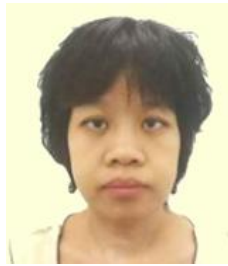

L. Ponthip obtained her B.S. degree from Thammasat University, Bangkok, Thailand in 1994. She received the master of arts in geography at the Wertern Michigan University in 2002. She received the doctor of philosophy degree in media and Governance FROM Keio University in 2011.

In 2002-2007 and 2013, she worked at the Geoinformatics Center, Asian Institute of Tech. Thailand as a researcher in the field of an interactive GIS, database and project management. At present, she is a research fellow of Japan Society for the Promotion of Science hosted by International Digital Earth Applied Science Research Center at Chubu University.

Her research interests include database management, water-related disaster issues and geography information system and remote sensing applications for sustainable development.

F. Hiromichi graduated from Nagoya University in 1980 . He received the doctor of science degree in earth sciences from Nagoya University in 1987. $\mathrm{He}$ is a professor of Chubu University and serves as the director of International Digital Earth Applied Science Research Center (IDEAS) of Chubu Institute for Advanced Studies in natural disasters from April, 2011. Before joining Chubu University, he was as a professor of the Faculty of Policy Management of Keio University.

His current research interests include regional planning, ecological development, global environment issues and education for sustainable development from the view point of spatial information sciences.

He has served on secretary general of GIS Association Japan, on board of directors in International Society for Digital Earth, Center for Environment Information Sciences, and as an adjunct professor of Chinese Academy of Sciences. 